\title{
ML-7 attenuates airway inflammation and remodeling via inhibiting the secretion of Th2 cytokines in mice model of asthma
}

\author{
CHUANJUN HUANG ${ }^{1 *}$, ZEWEN ZHANG $^{2 *}$, LIUXIN WANG $^{3}, \mathrm{JU} \mathrm{LIU}^{4}, \mathrm{XIAODAN} \mathrm{GONG}^{5}$ and CAIQING ZHANG \\ ${ }^{1}$ Department of Respiratory Diseases, Shandong University of Traditional Chinese Medicine, Jinan, Shandong 250013; \\ ${ }^{2}$ Department of Medical Imaging and Nuclear Medicine, Shandong University, Jinan, Shandong 250014; \\ ${ }^{3}$ Department of Respiratory Medicine, The First People's Hospital of Jining, Jining, Shandong 272011; \\ ${ }^{4}$ Department of Medical Research Center; ${ }^{5}$ Department of Respiratory Diseases, Shandong \\ Provincial Qianfoshan Hospital, Jinan, Shandong 250014, P.R. China
}

Received September 18, 2017; Accepted December 1, 2017

DOI: $10.3892 / \mathrm{mmr} .2018 .8683$

\begin{abstract}
Previous studies have indicated that smooth muscle myosin light chain kinase (MLCK) has a prominent role in the regulation of smooth muscle contraction, which tends to be upregulated in asthma. In recent years, numerous studies have reported that MLCK is intimately connected with the immunoregulatory mechanism of $\mathrm{T}$ cells. The imbalance of Thelper type 1 cells (Th1)/Th 2 constitutes the immune-associated pathological basis of chronic asthma. Th2-associated cytokines, including interleukin- $4,-5,-13,-25$ and -33 , are involved in airway inflammation, hyperresponsiveness and remodeling, which leads to a progressive decline in lung function. The purpose of the present study was to verify whether inhibition of bronchial MLCK attenuated the expression Th2-associated cytokines in asthmatic mice, including the above-mentioned ones. Female BALB/c mice were used to establish an ovalbumin (OVA)-induced model of asthma, of which one group was treated with the MLCK inhibitor (5-iodonaphthalene-1-sulfonyl) homopiperazine (ML-7). The inhibitor of MLCK, ML-7 attenuated airway inflammation and remodeling by reducing inflammatory cell infiltration and the secretion of Th2 cytokines in mice model of asthma, which may represent a promising therapeutic strategy for asthma.
\end{abstract}

Correspondence to: Professor Caiqing Zhang, Department of Respiratory Diseases, Shandong Provincial Qianfoshan Hospital, Shandong University, 16766 Jingshi Road, Jinan, Shandong 250014, P.R. China

E-mail: freezcq66@163.com

*Contributed equally

Key words: asthma, ML-7, Th2 cytokine, airway inflammation, airway remodeling

\section{Introduction}

Asthma is a chronic allergic lung disease and seizures are caused by the interaction of the environmental factors and a poor physical state. In the long run, severe irreversible structural airway alterations with a lack of responsiveness to treatment are frequently observed (1). Smooth muscle hypertrophy and hyperplasia are features of airway remodeling, which significantly contribute to the decline of lung function and frequent episodes of asthma attacks (2). Increasing levels of cytoskeletal proteins, inflammatory cytokines, enzymes, receptors and adhesion molecules have been reported to be associated with complex pathophysiology of asthma, including the myosin light chain kinase (MLCK) (3-6). Almost all eukaryotes produce MLCK, which is a $\mathrm{Ca}^{2+} /$ calmodulin-dependent protein kinase (CaMK) with a catalytic core and autoregulatory segments in the C-terminus. MLCK has a variety of different isoforms, the two major types of which are smooth-muscle MLCK (130-150 kDa) and nonmuscle MLCK (210-220 kDa), which are emanated from the same gene (7-9). The phosphorylation of MLC has an important role in airway smooth muscle contraction and relaxation $(10,11)$. It also promotes airway inflammation and airway remodeling by activating airway smooth muscle, fibroblasts and myoblasts, which subsequently secrete cytokines, chemokines and extracellular matrix (12). Previous studies have demonstrated that MLCK regulates numerous biological functions through up-regulation of NADPH oxidase, tumor necrosis factor receptor 2 signaling and notch signaling $(13,14)$. The signaling effect of MLCK in chronic asthma has been reported by several studies, including the regulation of the inflammatory response and vascular permeability (15). The mechanism of MLCK in smooth muscle cells and the immune regulation of $\mathrm{T}$ cells is complex, inducing a variety of cytokines in the occurrence and development of disease (16,17). (5-Iodonaphthalene-1-sulfonyl) homopiperazine (ML-7), a membrane-permeable agent, is customarily used as an MLCK inhibitor (18-20). This inhibitor combines with the catalytic perssad of the MLCK and then decreases the activity of the enzyme and is frequently applied in animal and cytological experiments $(21,22)$. 
In asthma, the imbalance of the proportion of T-helper type 1 (Th1) to Th2 cells activates the $\mathrm{CD}^{+}{ }^{+} \mathrm{Th} 2$ cell immune response and the release of interleukin (IL)-13, -25, -5, -4 and -33 , prompting the transformation of B cells into immunoglobulin (Ig)E-secreting cells $(23,24)$. Among these ILs, IL-25 and -33 are known as vital pro-inflammatory mediators that induce the release of Th2-associated cytokines, including IL-5, IL-4 and IL-13, which elevate serum IgE, as well as airway hyperresponsiveness, remodeling and mucus hypersecretion (25-28). However, in asthma, little is known regarding the correlation of MLCK with Th2 cytokines.

Based on the above, the present study hypothesized that MLCK accelerates airway remodeling through the induction of Th2 cytokines, which may be one of the mechanisms underlying the pathogenesis of asthma.

\section{Materials and methods}

Reagents and instruments. Anti-MLCK monoclonal antibody (cat. no. ab34829), anti- $\alpha$-SMA monoclonal antibody (mouse; cat. no. ab62736) and anti-collagen-I monoclonal antibody (mouse; cat. no. ab48262) were provided by Abcam (Cambridge, UK), while goat monoclonal GAPDH antibody (cat. no. AG019-1) was from Bioworld Technology Inc. (St Louis Park, MN, USA). Horseradish peroxidase-conjugated secondary antibody (goat anti-rabbit cat. no. ZB-2301) were purchased from Zhongshan Jinqiao Biotechnology Co., Ltd. (Beijing, China). ML-7 and ovalbumin (OVA) were obtained from Sigma-Aldrich (Merck KGaA, Darmstadt, Germany). IL-4 (cat. no. ZC-23216), IL-5 (cat. no. ZC-23228), IL-13 (cat. no. ZC-23211), IL-25 (cat. no. ZC-23312) and IL-33 (cat. no. ZC-23142) ELISA kits were from Proteintech Group, Inc. (Chicago, IL, USA). Polyvinylidene fluoride (PVDF) membranes were purchased from Cell Signaling Technology, Inc. (Danvers, MA, USA). Enhanced chemiluminescence (ECL) reagents were obtained from Solarbio Science \& Technology Co., Ltd. (Beijing, China). The BX51T light microscope and High-Speed Centrifuge PIC017 were respectively provided by Olympus Corp. (Tokyo, Japan) and Heraeus Corp. (Berlin, Germany).

Animal experiment. All animal experiments and surgical procedures were approved by the Institutional Animal Care and Use Committee of Shandong University (Shangdong China). A total of 45 healthy female BABL/c mice (weight, 20-28 g; age, 6-8 weeks) were obtained from the Animal Centre of Shandong University. The animals were bred in a temperature- and humidity-controlled room, and given ample food and tap water for the duration of the experimental session. Mice were allowed a week to adapt to the environment prior. The mice were randomly divided into three groups: The control group (PBS treatment), the OVA group (OVA challenge+PBS treatment) and the OVA+ML-7 group (OVA challenge+ML-7 treatment). The asthmatic models were established by challenge with OVA. Mice in the OVA and OVA+ML-7 groups were sensitized on days 1,8 and 15 by intraperitoneal injection with $100 \mu \mathrm{g}$ OVA adsorbed to $1 \mathrm{mg}$ aluminum hydroxide. After the last sensitization, the mice were treated with $1 \%$ OVA aerosol inhalation for up to $30 \mathrm{~min}$ per day for 7 consecutive days. The mice in the control group were exposed to an equivalent amount of PBS instead. In the OVA+ML-7 group, mice were given a daily intraperitoneal injection of ML-7 $(0.5 \mathrm{mg} / \mathrm{kg}$ in $0.5 \mathrm{ml} \mathrm{PBS}$ ) prior to OVA inhalation challenge for the next 7 days. All of the mice were euthanized at $24 \mathrm{~h}$ after the final challenge.

Bronchoalveolar lavage fluid (BALF) analysis. After the mice were euthanized, collection of BALF was performed immediately with isotonic sterile PBS lavage for four times $(0.5 \mathrm{ml}$ each time). From each mouse, $2 \mathrm{ml}$ BALF was collected separately. The cellular influx in the BALF was examined by using a cell counting plate. After centrifugation at $3,000 \mathrm{xg}$ for $8 \mathrm{~min}$ at $37^{\circ} \mathrm{C}$. After removing the supernatant, the precipitation cells were evenly spread on a slide and stained with $0.5 \mathrm{ml}$ Wright-Giemsa reagent, which contains $0.5 \mathrm{~g}$ Wright pigment, $0.5 \mathrm{~g}$ giemsa pigment and $500 \mathrm{ml}$ methanol for $1 \mathrm{~min}$ at $37^{\circ} \mathrm{C}$. Cells were identified based on morphological features and counted in randomly selected areas of the slide using light microscopy. The levels of IL-4, IL-5, IL-13, IL-25 and IL-33 were measured in the supernatant of BALF using ELISA kits.

Tissue samples. After the last challenge, the right lungs were removed from the chest cavity and immersed in $10 \%$ neutral buffered formalin at $25^{\circ} \mathrm{C}$ for $24 \mathrm{~h}$. Lung samples were then embedded in paraffin and sectioned by using a microtome $(5-\mu \mathrm{m})$. After dewaxing in xylene, rehydrating in graded ethanol, the sections were stained with haematoxylin at $25^{\circ} \mathrm{C}$ for $3 \mathrm{~min}$ and eosin at $25^{\circ} \mathrm{C}$ for $30 \mathrm{sec}$ to assess the infiltration of inflammatory cells. All images were assessed at a magnification of $\mathrm{x} 20$.

ELISA. The left eye of the mice was removed for blood collection. After low-temperature centrifugation at $3,000 \mathrm{x} \mathrm{g}$ at $4^{\circ} \mathrm{C}$ for $8 \mathrm{~min}$, the serum was obtained to determine the levels of OVA-specific (OVA-s) IgE using an ELISA kit (cat. no. YP-45821) purchased from Zhongshan Jinqiao Biotechnology Co., Ltd., within $24 \mathrm{~h}$ after final challenge. The levels of IL-4, $-5,-13,-25$ and -33 in the supernatant of BALF were assayed with ELISA kits according to the manufacturer's protocols.

Western blot analysis. The left lung tissue (10 mg) was minced and lysed in ice-cold radioimmunoprecipitation buffer containing1 mM phenylmethanesulfonyl fluoride, $1.5 \mathrm{M} \mathrm{NaCl}$, 10\% NP-40, 10 mM EDTA, 0.5 M Tris-HCl, (pH 7.4), 2.5\% deoxycholic acid, and protease inhibitors (1:100 dilution) and protease inhibitors in order to isolate total protein, which was used to analyze the content of $\alpha$-SMA and collagen-I. A total of $100 \mu \mathrm{g}$ protein was suspended in $5 \mathrm{X}$ reducing sample buffer, followed by boiling for $3 \mathrm{~min}$, and the proteins were centrifuged at $15,000 \mathrm{x} \mathrm{g}$ for $30 \mathrm{~min}$ at $4^{\circ} \mathrm{C}$ to obtain the supernatant for western blot analysis. The concentration of total protein was assessed by BCA protein assay, $10 \mu 1$ protein loaded per lane for separation by $8 \%$ SDS-PAGE acrylamide gel and subsequent transfer to a polyvinylidene difluoride membrane (Thermo Fisher Scientific, Inc.). After a blocking at $37^{\circ} \mathrm{C}$ for $2 \mathrm{~h}$ using $5 \%$ non-fat dried milk, and the membrane was incubated with rabbit polyclonal $\alpha$-SMA $(1: 1,000$ dilution in TBST), collagen-I (1:500 dilution in TBST) and GAPDH antibody (1:3,000 dilution) at $4^{\circ} \mathrm{C}$ overnight. After washing with 
Tris-buffered saline containing Tween-20, (TBST; pH 8.0) three times, the membranes were incubated with horseradish peroxidase-labeled goat anti-rabbit IgG as the secondary antibody (1:6,000 dilution in TBST) at room temperature for $2 \mathrm{~h}$. The ECL method (ECL kit; Solarbio Science \& Technology, Beijing, China) was used to develop the bands, and the gray value was determined with Image-Pro Plus 7.0 image analysis software (Media Cybernetics, Rockville, MD, USA). The expression levels of $\alpha$-SMA and collagen-I were normalized to those of GAPDH.

Reverse transcription-quantitative polymerase chain reaction (RT-qPCR). RT-qPCR was used to analyze the transcript levels of MLCK, $\alpha$-SMA and collagen-I. The total RNA was isolated from the lung tissues using TRIzol reagent based on the manufacturer's protocol. Then RNA samples were treated with DNase I (Takara Bio Inc., Otsu, Japan) for $30 \mathrm{~min}$ at $37^{\circ} \mathrm{C}$ to remove genomic DNA contamination. Thereafter, complementary (c)DNA was generated via RT reaction by using a PrimeScript first-strand cDNA synthesis kit (Invitrogen; Thermo Fisher Scientific, Inc., Waltham, MA, USA) following the manufacturer's protocol. PCR was performed with a Bio-Rad CFX96 Touch q-PCR system (Bio-Rad Laboratories, Inc., Hercules, CA, USA). The reaction mixture contained primers $[1.0 \mu \mathrm{l}$ of a $10 \mu \mathrm{mol} / 1$ stock including forward and reverse (Table I)], $0.15 \mu \mathrm{l} 1 \mu \mathrm{g} / \mu \mathrm{l}$ Taq DNA polymerase, $5.0 \mu \mathrm{l}$ 5X PCR buffer, $5.0 \mu \mathrm{l}$ of a $1 \mu \mathrm{g} / \mu \mathrm{l}$ solution of cDNA template and $13.85 \mu 10.1 \%$ diethylpyrocarbonate-treated water. The PCR process is as follows: Initial denaturation at $95^{\circ} \mathrm{C}$ for $60 \mathrm{sec}$, followed by 40 cycles of denaturation at $95^{\circ} \mathrm{C}$ for $5 \mathrm{sec}$, annealing at $65^{\circ} \mathrm{C}$ for $30 \mathrm{sec}$, and extension at $72^{\circ} \mathrm{C}$ for $120 \mathrm{sec}$. Fluorescence signals were collected at each annealing and elongation step. The relative transcriptional levels were finally calculated from quantification cycle values using the $2^{-\Delta \Delta \mathrm{Cq}}$ method (29).

Statistical analysis. All statistical analyses were performed using SPSS version 17.0 (SPSS, Inc., Chicago, IL, USA). Values are expressed as the mean \pm standard deviation. The levels of cytokines and the quantity of MLCK were analyzed by one-way analysis of variance followed by Dunnett's test. Differences between groups were considered statistically significant at $\mathrm{P}<0.05$. All experiments were repeated three times unless otherwise stated.

\section{Results}

$M L-7$ reduces airway inflammation and accumulation of inflammatory cells in a murine model of asthma. The murine model of airway inflammation was established through repetitive OVA sensitization. Thereby, an asthmatic phenotype similar to that observed in human asthma was established. Histological analysis of H\&E-stained lung tissue indicated that OVA induced inflammatory cell infiltration and pathological transformation in the lung tissues. However, treatment of OVA-challenged mice with ML-7 significantly alleviated the degree of tissue inflammation and infiltration. Furthermore, the pathological changes were milder (Fig. 1). The serum levels of OVA-s IgE in the OVA group were significantly higher compared with those in the control group
(131.46 \pm 10.72 vs. $25.37 \pm 4.89 \mathrm{ng} / \mathrm{ml} ; \mathrm{P}=0.004$; Fig. $2 \mathrm{~A})$. Based on the histological and serological analysis, it was determined that the model was successfully established. The total number of inflammatory cells, including neutrophils, eosinophils, macrophages and lymphocytes in the BALF, are hallmarks of inflammation in the mice at the cellular level. Particularly eosinophils are generally considered the hallmark of the onset of asthma. Compared with the control group, the total number of cells and eosinophils increased in the OVA group ( $\mathrm{P}<0.001$ for each comparison; Fig. 2B and $\mathrm{C}$ ). Of note, the percentage of eosinophils in the OVA+ML-7 group was significantly decreased compared with that in the OVA group $(0.012 \pm 0.007$ vs. $0.068 \pm 0.01 ; \mathrm{P}=0.0075 ;$ Fig. $2 \mathrm{C})$. The total number of cells and the percentage of neutrophils in the OVA + ML-7 group was also decreased compared with that in the OVA group (Fig. 2B and D). This partly reflected that ML-7 inhibited the accumulation of eosinophils in asthma-like airway inflammation.

ML-7 decreases the production of Th2-associated cytokines in the OVA-induced asthma model. MLCK has been reported to be a key mediator that promotes the production of other cytokines. To investigate the correlation among the mediators (IL-4, -5, -13, -25 and -33 ), their levels in the BALF were assessed. The levels of Th2 cytokines in the OVA group were significantly increased compared with those in the control group ( $\mathrm{P}<0.05$ for each comparison; Fig. 3). However, treatment with ML-7 attenuated the OVA-induced increases in the cytokines $(\mathrm{P}<0.05$ for each comparison; Fig. 3$)$. This proved that administration of ML-7 inhibited Th2-associated inflammatory cytokine release.

ML-7 attenuates airway remodeling in a mouse model of asthma. In asthmatic airway remodeling, $\alpha$-SMA and collagen-I are significant pathogenic factors. The level of $\alpha$-SMA and collagen-I in the lung tissue of mice in the OVA+ML-7 group was significantly reduced compared with that in the OVA group as demonstrated by western blot analysis $(\mathrm{P}<0.001$ for each comparison; Fig. $4 \mathrm{~A}$ and $\mathrm{B})$. The changes in $\alpha$-SMA and collagen-I expression levels were further confirmed by RT-qPCR analysis of lung tissue. The expression of mRNA of $\alpha$-SMA and collagen-I in asthmatic mice was significantly higher than that in the control group $(\mathrm{P}<0.05$ for each comparison; Fig. 4). In addition, the mRNA expression of $\alpha$-SMA and collagen-I in the OVA+ML-7 group was significantly lower than that in the OVA group $(\mathrm{P}<0.05$ for each comparison; Fig. 4). The above results demonstrated that inhibition of MLCK markedly inhibited airway remodeling in the OVA-induced asthma model.

ML-7 treatment completely inhibits OVA-induced upregulation of MLCK. MLCK has a key role in the regulation of smooth muscle contraction, and is mainly distributed in the bronchus where it stimulates smooth muscle cells. The expression of MLCK in the lung tissue of mice was examined using RT-qPCR. The results revealed that the expression of MLCK mRNA in mice in the OVA group was significantly higher than that in the control and OVA+ML-7 groups $(5.05 \pm 0.72$ vs. $1.21 \pm 0.37 ; \mathrm{P}=0.001 ;$ Fig. $4 \mathrm{C}$ ). Compared with that in the control group, the expression of MLCK in the OVA+ML-7 
Table I. Sequences of primers used for polymerase chain reaction.

\begin{tabular}{llll}
\hline Gene & Direction & Primer & Product length (bp) \\
\hline MLCK & Forward & 5'-ACATCCGTCAGGAGATCAG-3 & 172 \\
& Reverse & 5'-CACTCCGCTCTGTTAGCTC-3' & 542 \\
C-SMA & Forward & 5'-CTGTCCCTCTATGCCTCTGG-3' & 598 \\
& Reverse & 5'-AGGGCTGTGATCTCCTTCTG-3' & 391 \\
GAPDH & Forward & 5'-TAAAGGGTCATCGTGGCTTC-3' & 391 \\
& Reverse & 5'-GACGGCTGAGTAGGGAACAC-3' &
\end{tabular}

SMA, smooth muscle actin; MLCK, myosin light chain kinase.
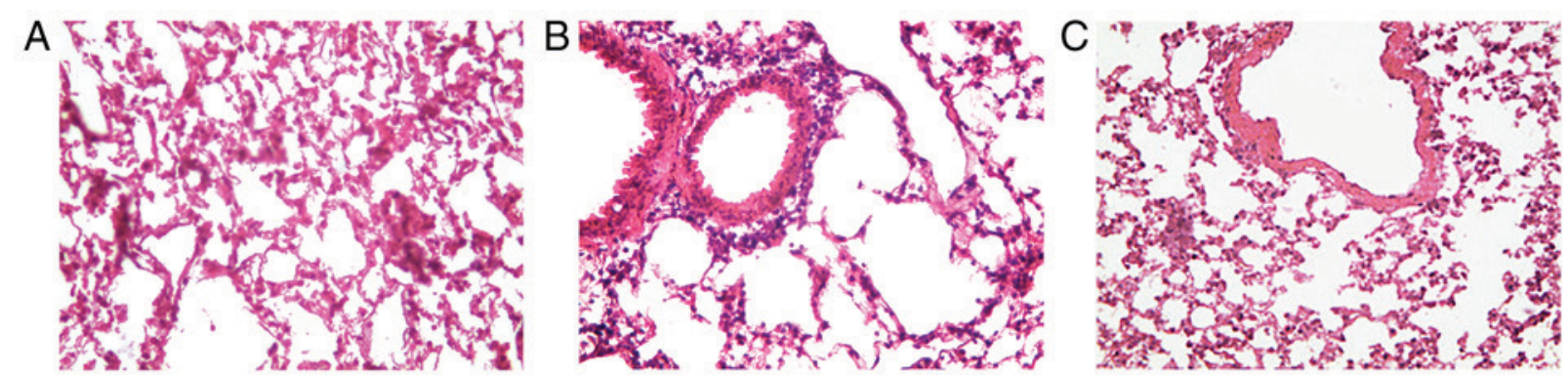

Figure 1. Effect of ML-7 on lung tissue of mice with OVA-induced asthma. Lung tissue sections obtained from mice at $24 \mathrm{~h}$ after the last OVA challenge were stained with H\&E (magnification, x200). (A) Control group; (B) OVA group; (C) OVA+ML-7 group. OVA, ovalbumin; ML-7, (5-iodonaphthalene-1-sulfonyl) homopiperazine.
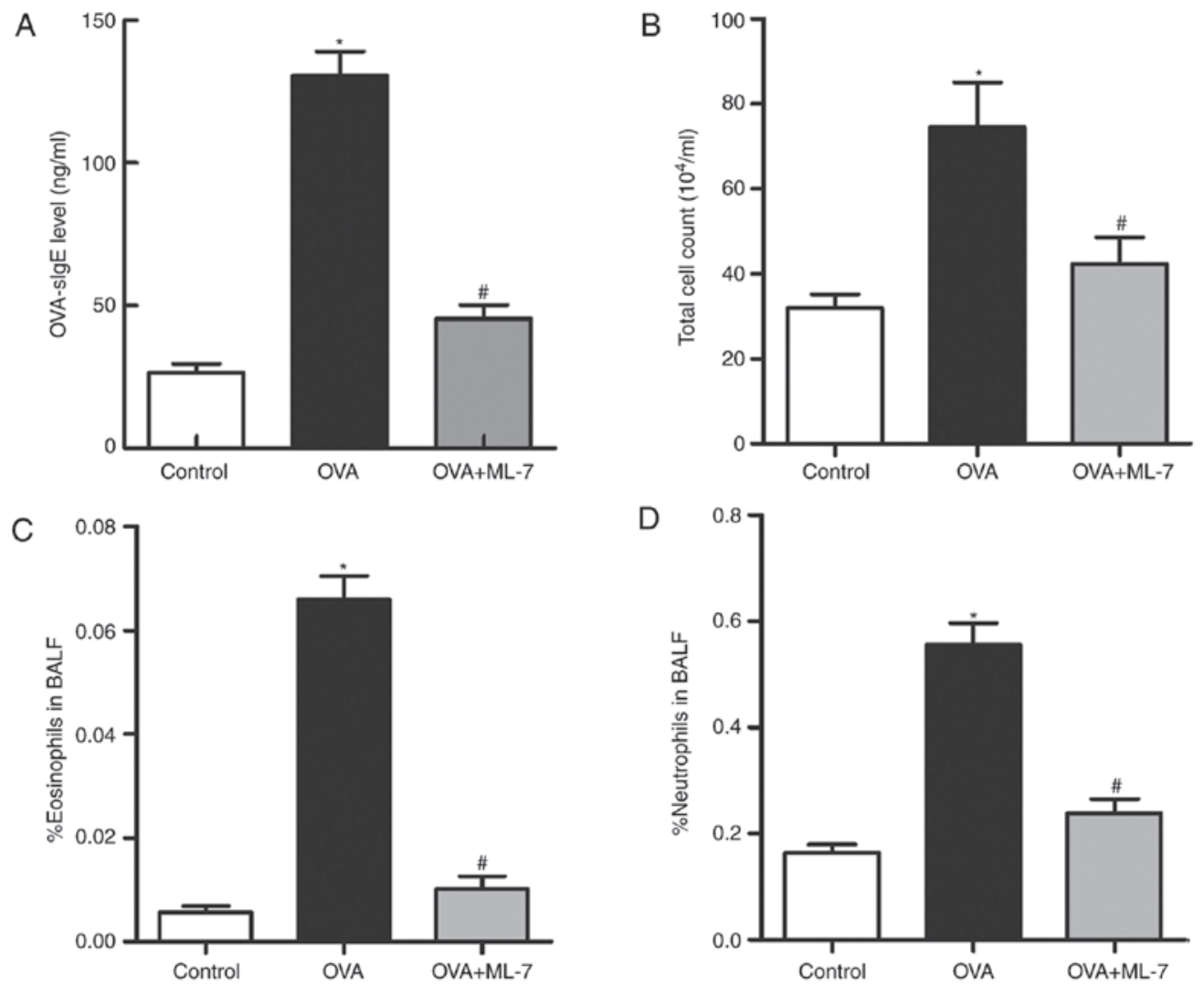

Figure 2. ML-7 reduces OVA-induced airway inflammation. (A) Level of OVA-s IgE in serum. (B) Total cell count, (C) percentage of eosinophils and (D) percentage of neutrophils in BALF after the final challenge. ${ }^{~} \mathrm{P}<0.05$ vs. control, ${ }^{\prime \prime} \mathrm{P}<0.05$ vs. OVA group. OVA-s, ovalbumin-specific; Ig, immunoglobulin; ML-7, (5-iodonaphthalene-1-sulfonyl) homopiperazine; BALF, bronchoalveolar lavage fluid. 
A

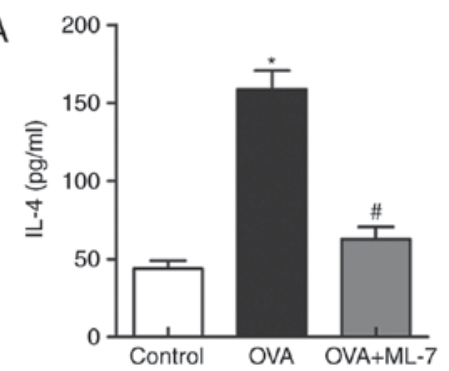

B

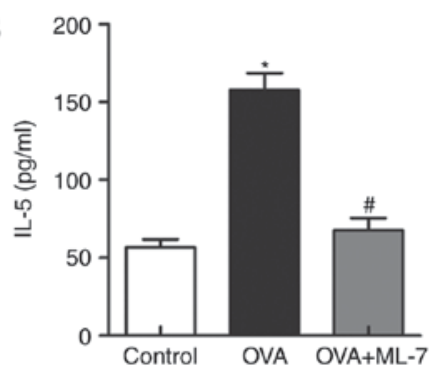

C

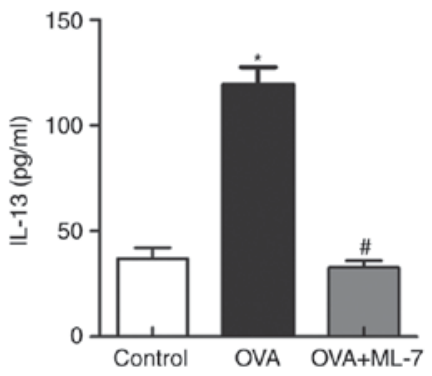

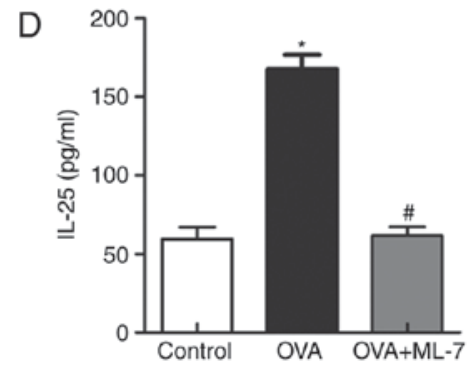

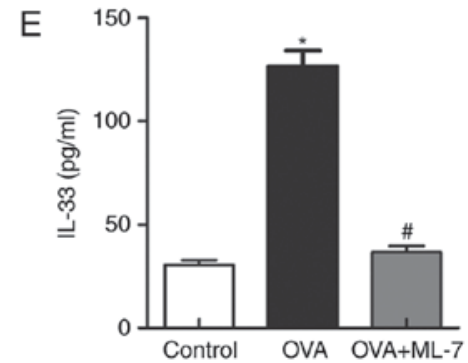

Figure 3. Inhibition of smooth muscle myosin light chain kinase by ML-7 reduces the production of T-helper type 2 cell-associated cytokines in an OVA-induced asthma model. The concentrations of (A) IL-4, (B) IL-5, (C) IL-13, (D) IL-25 and (E) IL-33 were analyzed by ELISAs. ${ }^{*} \mathrm{P}<0.05$ vs. control, " $\mathrm{P}<0.05$ vs. OVA group. OVA, ovalbumin; ML-7, (5-iodonaphthalene-1-sulfonyl) homopiperazine; IL, interleukin.

A
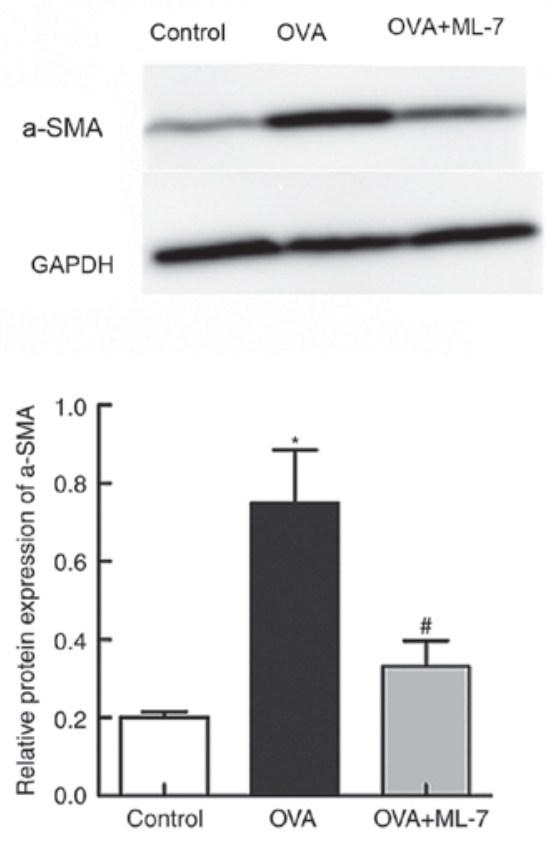

B

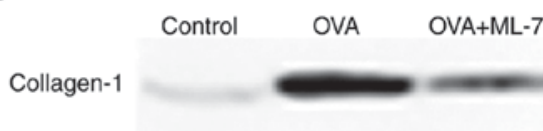

GAPDH

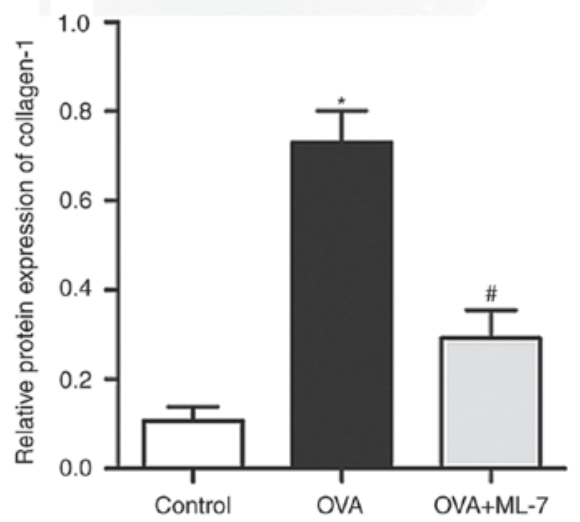

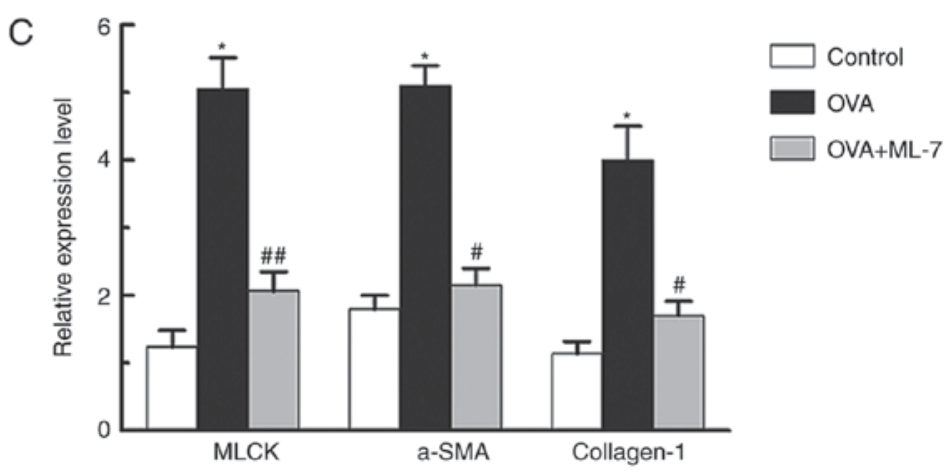

Figure 4. ML-7 attenuates airway remodeling in a mouse model of asthma. The protein expression of $\alpha$-SMA and collagen-I in lung tissue, as detected by (A and B) western blot analysis and (C) reverse transcription-quantitative polymerase chain reaction. ${ }^{*} \mathrm{P}<0.05$ vs. control, ${ }^{\sharp} \mathrm{P}<0.05$, ${ }^{\#} \mathrm{P}<0.01 \mathrm{vs}$. OVA group. OVA, ovalbumin; ML-7, (5-iodonaphthalene-1-sulfonyl) homopiperazine; $\alpha$-SMA, $\alpha$-smooth muscle actin. 


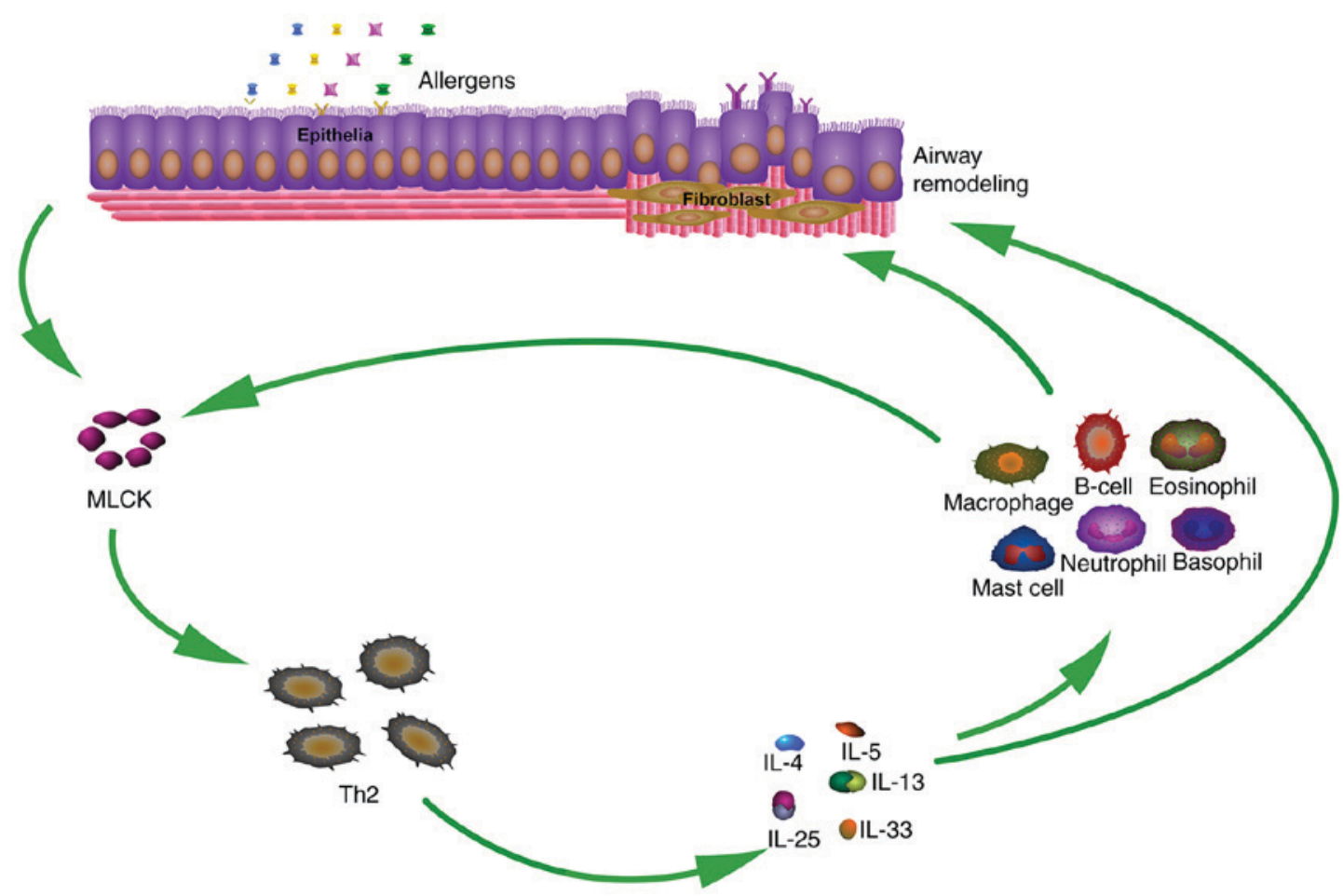

Figure 5. Schematic depicting signaling pathways of MLCK. MLCK catalyzes the production of IL-4, IL-5, IL-13, IL-25 and IL-33 by Th2 cells and the cytokines act on inflammatory cells to increase the secretion of MLCK and accelerate airway remodeling, or directly accelerate airway remodeling. MLCK, myosin light chain kinase; IL, interleukin; Th2 cells, T-helper type 2 cells.

group was not significantly different $(1.91 \pm 0.52$ vs. $1.21 \pm 0.37$; $\mathrm{P}=0.95$; Fig. 4C), indicating that ML-7 treatment completely inhibited OVA-induced upregulation of MLCK.

\section{Discussion}

Previous studies indicated that MLCK is involved in a variety of T-cell immune responses in various diseases and has a central role in asthmatic inflammation. The level of MLCK was reported to be correlated with the severity and susceptibility to asthma (15). The results of the present study demonstrated that ML-7 inhibited airway inflammation and remodeling in an OVA-induced mouse model of asthma. First, it was revealed that the expression of MLCK was significantly higher in OVA-challenged mice compared with that in control mice. Furthermore, the downregulation of MLCK by ML-7 had a directly effect on the expression and secretion of $\alpha$-SMA and collagen-I, which are indicators of airway remodeling (30).

Asthma, which is a chronic airway inflammatory disease, occurs with a predominant Th 2 immunity and the imbalance of Th1/Th2 is the immune pathological basis of chronic asthma. MLCK is regarded as a cytoskeletal effector, which is the key pathophysiologic feature of asthma, including the regulation of the inflammatory response, vascular permeability and smooth muscle proliferation (31). In the present study, the level of MLCK in the lungs of chronic asthma model mice was elevated compared with that in the control group, and the inhibition of MLCK activity by ML-7 significantly reduced inflammatory cell infiltration. Inflammatory cytokines and mediators are released by gathering inflammatory cells in the airway, which may lead to mucus hypersecretion, increases in bronchial hyperresponsiveness and airway reconstitution (32). Numerous studies have demonstrated that the accumulation of IL-25 and -33 in asthma may stimulate the production of IL-4, -5 and -13 via innate immune cells or other pathways, and that anti-IL-25 or anti-IL-33 significantly reduced the levels of IL-4, -5 and -13 (27,33). In the present study, inhibition of MLCK activity by ML-7 also decreased the content of IL-25 and -33 . This series of links revealed a positive correlation between MLCK and Th2 cytokines, implying that the expression of MLCK is involved in a portion of asthmatic immune responses, accelerating airway inflammation and lung remodeling.

Clinically, airway remodeling causes a progressive and irreversible loss of lung function, but the pathogenesis has remained to be fully elucidated. The interaction of cytokines in the airway leads to bronchoconstriction, which is thought to gradually contribute to airway remodeling, including airway smooth muscle hyperplasia, hypertrophy and goblet cell multiplication (34). Among these ILs, IL-4 activates mast cells and basophils, which are involved in triggering asthma by developing effector $\mathrm{T}$ cell responses, eosinophil chemotaxis and IgE accumulation. IL-4 may modify the differentiation of undifferentiated Th0 cells into Th 2 cells, as well as the subsequent production of cytokines and mediators implicated in airway inflammation and obstruction (35). IL-5 is a key mediator that participates in terminal differentiation and maturation of eosinophils, and prolongs the survival of the cells in allergic tissues. It may augment Ig conglutination by binding to the IL-5 receptor and promote the growth of B cells (36). IL-13 enhances mucus production, induces goblet cell differentiation and promotes IgE synthesis (37). IL-25 and -33 are Th2-associated cytokines, which may accelerate 
airway remodeling via numerous mechanisms. IL-25 induces airway remodeling via complex mechanisms involving the enhancement of the expression of a series of mediators, including connective tissue growth factor and transforming growth factor, and subsequent increases in extracellular matrix proteins, including fibronectin and collagen-I, -III and -V (38). IL-33 exacerbates airway remodeling by activating human lung fibroblasts, which leads to upregulation of collagen-I in asthma (39). In the present study, the levels of Th2 cytokines were elevated in asthmatic model mice, which was inhibited by treatment with ML-7. In addition, the expression of $\alpha$-SMA and collagen-I, also exhibited such a trend. All of the present results suggested that ML-7, a specific inhibitor of MLCK activity, was able to attenuate asthma-associated airway inflammation and remodeling to a certain extent by regulating the secretion of Th2-associated cellular immunomodulatory factors which are vital in eosinophil accumulation, mucus production, airway hyperresponsiveness and are key stimulants in $\mathrm{IgE}$ synthesis by $\mathrm{B}$ cells. (Fig. 5).

Taken together, the present study revealed that MLCK affected the development of OVA-induced airway inflammation and remodeling in a mouse model by promoting the release of the Th2 cytokines IL-4, -5, -13, -25 and -33 . Treatment with the MLCK inhibitor ML-7 exerted protective effects against allergic airway inflammation and remodeling in lung tissues, suggesting that it is a potential therapeutic candidate for the treatment of asthma.

\section{Acknowledgements}

Not applicable.

\section{Funding}

The present study was supported by the Natural and Science Foundation of Shandong Province, China (grant no. ZR2014HL003).

\section{Availability of data and materials}

The analyzed data sets generated during the study are available from the corresponding author on reasonable request.

\section{Authors' contributions}

$\mathrm{CH}, \mathrm{ZZ}$ and $\mathrm{CZ}$ conceived and designed the experiments. $\mathrm{CH}$, $\mathrm{ZZ}, \mathrm{LW}$ and $\mathrm{XG}$ performed the experiments. $\mathrm{CH}, \mathrm{ZZ}$ and JL analyzed the data. $\mathrm{LW}, \mathrm{JL}, \mathrm{XG}$ and $\mathrm{CZ}$ contributed reagents, materials and analysis tools. $\mathrm{CH}, \mathrm{ZZ}$ and $\mathrm{CZ}$ wrote the paper.

\section{Ethics approval and consent to participate}

All animal experiments and surgical procedures were approved by the Institutional Animal Care and Use Committee of Shandong University (Shangdong China).

\section{Consent for publication}

Not applicable.

\section{Competing interests}

All authors declare that they have no competing interests.

\section{References}

1. Yang ZC, Yi MJ, Shan YC, Wang C, Ran N, Jin LY, Fu P, Feng XY, Xu L and Qu ZH: Targeted inhibition of Six1 attenuates allergic airway inflammation and remodeling in asthmatic mice. Biomed Pharmacother 84: 1820-1825, 2016.

2. Tabeling C, Herbert J, Hocke AC, Lamb DJ, Wollin SL, Erb KJ, Boiarina E, Movassagh H, Scheffel J, Doehn JM, et al: Spleen tyrosine kinase inhibition blocks airway constriction and protects from Th2-induced airway inflammation and remodeling. Allergy 72: 1061-1072, 2017.

3. Jang YH, Choi JK, Jin M, Choi YA, Ryoo ZY, Lee HS, Park PH, Kim SU, Kwon TK, Jang MH, et al: House dust mite increases pro-Th2 cytokines, IL-25 and IL-33 via the activation of TLR1/6 signaling. J Invest Dermatol 137: 2354-2361, 2017.

4. Ujino M, Sugimoto N, Koizumi Y, Ro S, Kojima Y, Asae KH, Yamashita N, Ohta K and Nagase H: Leukotriene receptor antagonist attenuated airway inflammation and hyperresponsiveness in a double-stranded RNA-induced asthma exacerbation model. Allergol Int 66S: S21-S26, 2017.

5. Khapchaev AY and Shirinsky VP: Myosin light chain kinase MYLK1: Anatomy, interactions, functions, and regulation. Biochemistry (Mosc) 81: 1676-1697, 2016.

6. Inam A, Shahzad M, Shabbir A, Shahid H, Shahid K and Javeed A: Carica papaya ameliorates allergic asthma via down regulation of IL-4, IL-5, eotaxin, TNF- $\alpha$, NF-kB, and iNOS levels. Phytomedicine 32: 1-7, 2017.

7. Wang J, Weigand L, Foxson J, Shimoda LA and Sylvester JT: $\mathrm{Ca} 2+$ signaling in hypoxic pulmonary vasoconstriction: Effects of myosin light chain and Rho kinase antagonists. Am J Physiol Lung Cell Mol Physiol 293: L674-L685, 2007.

8. Zhang WC, Peng YJ, Zhang GS, He WQ, Qiao YN, Dong YY, Gao YQ, Chen C, Zhang CH, Li W, et al: Myosin light chain kinase is necessary for tonic airway smooth muscle contraction. J Biol Chem 285: 5522-5531, 2010

9. Alcala DB, Haldeman BD, Brizendine RK, Krenc AK, Baker JE, Rock RS and Cremo CR: Myosin light chain kinase steady-state kinetics: Comparison of smooth muscle myosin II and nonmuscle myosin IIB as substrates. Cell Biochem Funct 34: 469-474, 2016.

10. Connolly SC, Smith PG, Fairbank NJ, Lall CA, Cole DJ, Mackinnon JD and Maksym GN: Chronic oscillatory strain induces MLCK associated rapid recovery from acute stretch in airway smooth muscle cells. J Appl Physiol (1985) 111: 955-963, 2011.

11. Flores C, Ma SF, Maresso K, Ober C and Garcia JG: A variant of the myosin light chain kinase gene is associated with severe asthma in African Americans. Genet Epidemiol 31: 296-305, 2007.

12. Gao L, Grant AV, Rafaels N, Stockton-Porter M, Watkins T, Gao P, Chi P, Muñoz M, Watson H, Dunston G, et al: Polymorphisms in the myosin light chain kinase gene that confer risk of severe sepsis are associated with a lower risk of asthma. J Allergy Clin Immunol 119: 1111-1118, 2007.

13. Suzuki M, Nagaishi T, Yamazaki M, Onizawa M, Watabe T, Sakamaki Y, Ichinose S, Totsuka M, Oshima S, Okamoto R, et al: Myosin light chain kinase expression induced via tumor necrosis factor receptor 2 signaling in the epithelial cells regulates the development of colitis-associated carcinogenesis. PLoS One 9: e88369, 2014

14. Basu S and Proweller A: Autoregulatory control of smooth muscle myosin light chain kinase promoter by notch signaling. J Biol Chem 291: 2988-2999, 2016.

15. Zhou T, Wang T and Garcia JG: A nonmuscle myosin light chain kinase-dependent gene signature in peripheral blood mononuclear cells is linked to human asthma severity and exacerbation status. Pulm Circ 5: 335-338, 2015.

16. Clayburgh DR, Barrett TA, Tang Y, Meddings JB, Van Eldik LJ, Watterson DM, Clarke LL, Mrsny RJ and Turner JR: Epithelial myosin light chain kinase-dependent barrier dysfunction mediates T cell activation-induced diarrhea in vivo. J Clin Invest 115: 2702-2715, 2005

17. Wang T, Moreno-Vinasco L, Ma SF, Zhou T, Shimizu Y, Sammani S, Epshtein Y, Watterson DM, Dudek SM and Garcia JG: Nonmuscle myosin light chain kinase regulates murine asthmatic inflammation. Am J Respir Cell Mol Biol 50: 1129-1135, 2014. 
18. Khapchaev AY, Kazakova OA, Samsonov MV, Sidorova MV, Bushuev VN, Vilitkevich EL, Az'muko AA, Molokoedov AS, Bespalova ZD and Shirinsky VP: Design of peptidase-resistant peptide inhibitors of myosin light chain kinase. J Pept Sci 22: 673-681, 2016

19. Antoine TE and Shukla D: Inhibition of myosin light chain kinase can be targeted for the development of new therapies against herpes simplex virus type-1 infection. Antivir Ther 19: $15-29,2014$.

20. Feng L, Geisselbrecht Y, Blanck S, Wilbuer A, Atilla-Gokcumen GE, Filippakopoulos P, Kräling K, Celik MA, Harms K, Maksimoska J, et al: Structurally sophisticated octahedral metal complexes as highly selective protein kinase inhibitors. J Am Chem Soc 133: 5976-5986, 2011.

21. Odani K, Kobayashi T, Ogawa Y, Yoshida S and Seguchi H: ML-7 inhibits exocytosis of superoxide-producing intracellular compartments in human neutrophils stimulated with phorbol myristate acetate in a myosin light chain kinase-independent manner. Histochem Cell Biol 119: 363-370, 2003.

22. Cheng X, Wang X, Wan Y, Zhou Q, Zhu H and Wang Y: Myosin light chain kinase inhibitor ML7 improves vascular endothelial dysfunction via tight junction regulation in a rabbit model of atherosclerosis. Mol Med Rep 12: 4109-4116, 2015.

23. Chua YL, Liong KH, Huang CH, Wong HS, Zhou Q, Ler SS, Tang Y, Low CP, Koh HY, Kuo IC, et al: Blomia tropicalis-specific TCR transgenic Th2 cells induce inducible BALT and severe asthma in mice by an IL-4/IL-13-dependent mechanism. J Immunol 197: 3771-3781, 2016.

24. Ogasawara T, Hatano M, Satake H, Ikari J, Taniguchi T, Tsuruoka N, Watanabe-Takano H, Fujimura L, Sakamoto A, Hirata $\mathrm{H}$, et al: Development of chronic allergic responses by dampening Bcl6-mediated suppressor activity in memory $\mathrm{T}$ helper 2 cells. Proc Natl Acad Sci USA 114: E741-E750, 2017.

25. Tashiro H, Takahashi K, Hayashi S, Kato G, Kurata K, Kimura S and Sueoka-Aragane N: Interleukin-33 from monocytes recruited to the lung contributes to house dust mite-induced airway inflammation in a mouse model. PLoS One 11: e0157571, 2016.

26. Glück J, Rymarczyk B, Kasprzak M and Rogala B: Increased levels of interleukin-33 and thymic stromal lymphopoietin in exhaled breath condensate in chronic bronchial asthma. Int Arch Allergy Immunol 169: 51-56, 2016.

27. Salter BM, Oliveria JP, Nusca G, Smith SG, Tworek D, Mitchell PD, Watson RM, Sehmi R and Gauvreau GM: IL-25 and IL-33 induce type 2 inflammation in basophils from subjects with allergic asthma. Respir Res 17: 5, 2016.
28. Mahmutovic Persson I, Akbarshahi H, Menzel M, Brandelius A and Uller L: Increased expression of upstream TH2-cytokines in a mouse model of viral-induced asthma exacerbation. J Transl Med 14: 52, 2016.

29. Livak KJ and Schmittgen TD: Analysis of relative gene expression data using real-time quantitative PCR and the 2(-Delta Delta $\mathrm{C}(\mathrm{T})$ ) method. Methods 25: 402-408, 2001.

30. Guo Z, Wu J, Zhao J, Liu F, Chen Y, Bi L, Liu S and Dong L: IL-33 promotes airway remodeling and is a marker of asthma disease severity. J Asthma 51: 863-869, 2014.

31. Huang Y, Luo X, Li X, Song X, Wei L, Li Z, You Q, Guo Q and Lu N: Wogonin inhibits LPS-induced vascular permeability via suppressing MLCK/MLC pathway. Vascul Pharmacol 72: 43-52, 2015.

32. Walsh GM: Biologics targeting IL-5, IL-4 or IL-13 for the treatment of asthma-an update. Expert Rev Clin Immunol 13: 143-149, 2017.

33. Wang C,Liu Q, Chen F, Xu W,Zhang Cand Xiao W: IL-25 promotes Th2 immunity responses in asthmatic mice via nuocytes activation. PLoS One 11: e0162393, 2016.

34. Chung KF: Targeting the interleukin pathway in the treatment of asthma. Lancet 386: 1086-1096, 2015.

35. Bagnasco D, Ferrando M, Varricchi G, Passalacqua G and Canonica GW: A critical evaluation of anti-IL-13 and anti-IL-4 strategies in severe asthma. Int Arch Allergy Immunol 170: 122-131, 2016.

36. Papathanassiou E, Loukides S and Bakakos P: Severe asthma: Anti-IgE or anti-IL-5? Eur Clin Respir J 3: 31813, 2016.

37. Jia Y, Fang X, Zhu X, Bai C, Zhu L, Jin M, Wang X, Hu M, Tang R and Chen Z: IL-13+ type 2 innate lymphoid cells correlate with asthma control status and treatment response. Am J Respir Cell Mol Biol 55: 675-683, 2016.

38. Tang W, Smith SG, Beaudin S, Dua B, Howie K, Gauvreau G and O'Byrne PM: IL-25 and IL-25 receptor expression on eosinophils from subjects with allergic asthma. Int Arch Allergy Immunol 163: 5-10, 2014

39. Shan S, Li Y, Wang J, Lv Z, Yi D, Huang Q, Corrigan CJ, Wang W, Quangeng $Z$ and Ying S: Nasal administration of interleukin-33 induces airways angiogenesis and expression of multiple angiogenic factors in a murine asthma surrogate. Immunology 148: 83-91, 2016.

This work is licensed under a Creative Commons Attribution-NonCommercial-NoDerivatives 4.0 International (CC BY-NC-ND 4.0) License. 